\title{
Technical Nuances of Ventriculoatrial Shunt Using Seldinger Technique for Percutaneous Insertion of Distal Shunt Catheter
}

\author{
Yerragunta Thirumal ${ }^{1}$ Vamsi Krishna Yerramneni ${ }^{1}$ Ram Nadha Reddy Kanala ${ }^{1}$ \\ Vishwa Kumar Karanth ${ }^{1}$ Swapnil Kolpakwar ${ }^{1} \quad$ Vikram Manure Namdev $^{1}$ Rajesh Babu VV ${ }^{2}$ \\ 1Department of Neurosurgery, Nizam's Institute of Medical \\ Sciences, Hyderabad, Telangana, India \\ 2Department of Anesthesia, Nizam's Institute of Medical Sciences, \\ Hyderabad, Telangana, India

\begin{abstract}
Address for correspondence Vamsi Krishna Yerramneni, MCh, Department of Neurosurgery, Nizam's Institute of Medical Sciences, Panjagutta, Hyderabad, Telangana 500082, India (e-mail: vamsiky.ns@gmail.com).
\end{abstract}

Indian J Neurosurg:2020;9:230-232

\section{Abstract}

Keywords

- ventriculoatrial shunt

- Seldinger technique

- distal end
Introduction One of the most seen neurosurgical complications is the ventriculoperitoneal (VP) shunt failure. The cause can be often due to peritoneal malabsorption of cerebrospinal fluid. The next safer alternative is to place a ventriculoatrial (VA) shunt. Various methods of access to the right atrium had been described. The percutaneous method of insertion of distal catheter using Seldinger technique is a safer alternative to open method. We describe the percutaneous insertion of distal catheter using Seldinger technique, modifications in the method, and specific tools required for the insertion.

Clinical History The patient is a 22-year-old male who is a known case of tubercular meningitis with recurrent failure of VP shunt due to malabsorption at peritoneal end of catheter. During the last hospital visit, he presented with altered sensorium and computed tomography scan brain showed ventriculomegaly. He was planned for VA shunt placement.

Surgical Technique The insertion of ventricular end of the catheter is similar to any other shunt placement. The internal jugular vein (IJV) was punctured using introducer needle and guide wire was placed in the IJV at the level of T6-T7 and the serial dilators passed on the guide wire for creating a track for passage of shunt catheter. The shunt catheter was passed over the guide wire to the desired vertebral level and distal shunt catheter is connected proximally to the shunt catheter in the neck.

Conclusion The percutaneous insertion of distal catheter with serial dilators using Seldinger technique is a safe and effective method for VA shunt placement.

\section{Introduction}

The commonly used cerebrospinal fluid (CSF) diversion procedures are ventriculoperitoneal (VP) shunt, ventriculoatrial (VA) shunt, and ventriculopleural (VPL) shunt. VP shunt malfunctions could be due to various reasons and one of them could be the peritoneum inability to absorb the CSF. ${ }^{1}$ It is particularly the case when tuberculosis affecting the peritoneal absorptive capability. ${ }^{2}$ In such cases, the most preferred alternative is VA shunt compared with VPL shunt. ${ }^{3}$ VA shunt is not so often performed procedure. At authors institute, annual neurosurgical procedures are around 3,500 and VA shunts
Dol https://doi.org/

10.1055/s-0040-1713699

ISSN 2277-954X.
(C) 2020. Neurological Surgeons' Society of India.

This is an open access article published by Thieme under the terms of the Creative Commons Attribution-NonDerivative-NonCommercial-License, permitting copying and reproduction so long as the original work is given appropriate credit. Contents may not be used for commercial purposes, or adapted, remixed, transformed or built upon. (https://creativecommons.org/licenses/by-nc-nd/4.0/) Thieme Medical and Scientific Publishers Pvt. Ltd., A-12, 2nd Floor, Sector 2, Noida-201301 UP, India 
constitute hardly one or two among them. The technique of the procedure is always a matter of the concern when it is required. The authors in the current article describe the modification in the Seldinger technique for the placement of VA shunt they adopted in a case of recurrent VP shunt failure for a case of hydrocephalus as a sequalae to the tuberculosis. The ventricular end placement is same as for any other shunt placements, while the insertion of the shunt into right atrium (RA) part could be done minimally invasively using Seldinger technique. The authors described the modification in technique and the specific tools required for insertion of the atrial catheter in the current report.

\section{Clinical Details}

The patient is a 22-year-old male who is a known case of tubercular meningitis with hydrocephalus underwent VP shunt (Chhabra shunt, Surgiwear, Shahjahanpur, Uttar Pradesh, India) 2 years back. He had multiple abdominal end revisions 6 months back. Twice the shunt was placed in different parts of the peritoneum on the right side and finally it was placed on the left side of the abdomen. He had multiple admissions for shunt revisions. Lastly, he presented to emergency services with altered sensorium. Computed tomography (CT) brain showed ventriculomegaly, shunt chamber was refilling, and abdominal ultrasound scan showed CSF collection in the peritoneal cavity. Shunt abdominal end was exteriorized, and CSF was drained for few days. Patient regained consciousness and CSF analysis showed no meningitis. In view of the multiple abdominal end revisions and diminished capacity of the peritoneum to absorb CSF because of possible tuberculous abdomen, it was decided to place a VA shunt.

\section{Technique}

The patient was planned for right VA shunt. The patient is positioned in Trendelenburg position $\left(10-15^{\circ}\right)$ under general anesthesia. After thorough preparation, the ventricles were tapped and ventricular catheter (Chhabra shunt, Surgiwear, India) placed and connected to the distal catheter with chamber. The right internal jugular vein (IJV) was punctured percutaneously using introducer needle $(18 \mathrm{G}, 7 \mathrm{~cm})$ using standard anatomical landmarks. The guide wire $(0.965 \mathrm{~mm} \times$ $70 \mathrm{~cm}$ ) was passed into the needle up to T6-T7 vertebral level under fluoroscopy guidance with a close monitoring of electrocardiogram for any arrhythmias. A stab wound was made for entry of the serial dilators of size $10 \mathrm{~F} \& 12 \mathrm{~F}$. The introducer needle was removed keeping the guide in situ. The subcutaneous track was serially dilated using the hemodialysis catheter dilators from the hemodialysis catheter set (Mahurkar Acute dual lumen catheter kit, Covidien, Mansfield, Massachusetts, United States) (-Fig. 1) passing them on the guide wire and a track is made for the passage of shunt catheter. The dilator is removed keeping the guide wire in situ. The distal ventricular catheter is brought through the same stab wound made for venous puncture and the tube is cut measuring the approximate length up to the T6 vertebral level. The distal cut tube is guided into the IJV over the guide wire after cutting the tip

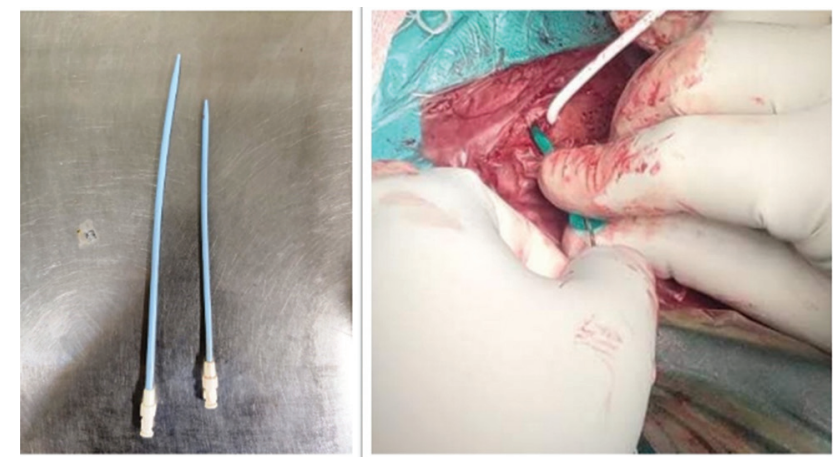

Fig. 1 Serial dilators and track dilatation using them.
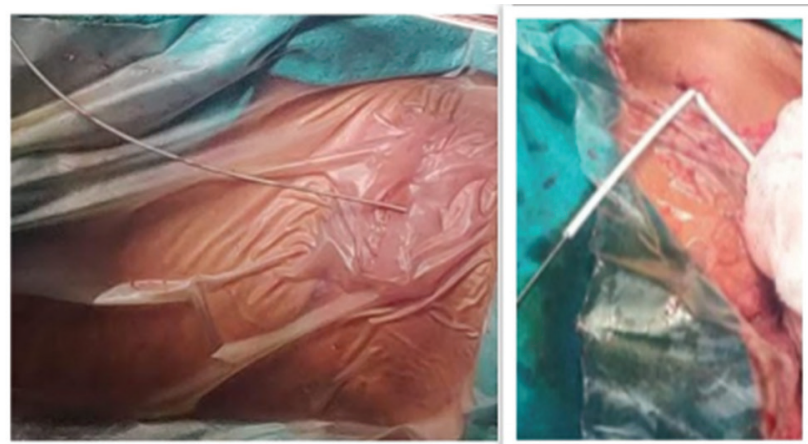

Fig. 2 Distal catheter insertion over the the guide wire.

of the tube and the guide wire removed ( - Fig. 2). The two cut ends of the catheter are connected using the connector and secured with a 2' 0 silk. Compression padding applied over the neck. Patient made an uneventful recovery. Postoperatively, the catheter tip position was confirmed by the chest X-ray and CT scan brain and patient discharged on day 3 .

\section{Discussion}

If we look back into the history of neurosurgical procedures, no other technique would have probably underwent so many changes than that of a CSF diversion technique. The idea of VA shunt was suggested by Gartner ${ }^{4}$ in the form of CSF diversion into venous or lymphatic system of neck a decade earlier than the first VP shunt by Kausch in 1905. Animal experiments by Pudenz demonstrated that the placement of distal tip of the catheter in IJV or superior vena cava can cause fibrous capsule formation at tip with blockage of tip of the catheter and occlusion of vein. ${ }^{5}$ Thus, the placement of catheter tip at RA had been standardized. Later in the year 1957 Pudenz introduced the VA shunt technique. ${ }^{6}$ To access the RA, although various routes like through external jugular vein, transverse sinus, or subclavian vein ${ }^{7}$ had been described, IJV had been the choice for many surgeons due to relatively less number of complications.

To get the access to the RA, Seldinger technique could be used that makes the procedure less risky and easily adoptable considering the fact that it is rarely done procedure. The authors in the present condition took the help of anesthesia colleagues who perform IJV punctures on routine basis to place central venous lines. 
The percutaneous technique for the placement of VA shunt was first described by Sorge et $\mathrm{al}^{8}$ using a special set based on the Seldinger technique and there are other reports that describe this technique., ${ }^{7,9,10}$ Each of these papers described the locally available various catheters and peel away sheaths to cannulate the IJV or subclavian vein for passing the distal end of the shunt into the superior vena cava.

The authors in the present paper describe a novel percutaneous technique of VA shunt placement with use of various serial dilators, cathters and other tools required. The dilator (Mahurkar acute dual lumen catheter kit, Covidien, Mansfield, Massachusetts, United States) used by the author has a serial dilator of 10 and $12 \mathrm{~F}$. The distal catheter of the shunt catheter (Chhabra shunt, Surgiwear, India) has an outer diameter of $7.5 \mathrm{~F}$ size. The tip of the distal end of the Chhabra shunt was cut in our case to be able to pass it over the guide wire. The other alternative that exists is the hemodialysis catheter dilators (Mahurkar Chronic Carbothane catheter kit, Covidien, Mansfield, Massachusetts, United States) or other central line catheter dilators of similar make that can be available in various sizes of 12,14 , or $16 \mathrm{~F}$. These catheter sets have a peel away sheath that permits the shunt distal end to pass into the IJV lot easier. The Mahurkar catheter is a cost-effective option but requires cutting of the shunt tip and manipulation of the shunt tube over the guide wire. These modifications in the technique proposed by the authors and tools that are available in the Indian market make the technique lot easier and simpler to perform.

\section{Conclusion}

VA shunt is a rarely performed procedure, and application of Seldinger technique using the serial dilators to pass the distal catheter to the RA makes the procedure simple and easily adaptable.

\section{Conflict of Interest}

None declared.

\section{References}

1 Guice KS, Kosloske AM, Turner P, Wachtel T. Recurrent pseudocyst from a ventriculoperitoneal shunt. An unusual abdominal mass. Am J Dis Child 1978;132(3):285-286

2 Takase H, Tatezuki J, Ikegaya N, et al. Critical ventriculo-peritonealshuntfailureduetoperitoneal tuberculosis:case reportand diagnostic suggestions for abdominal pseudocyst. Surg Neurol Int 2014;5(Supplement):7110.4103/2152-7806.132583

3 Ventriculoatrial Shunting - MedOne. Thieme. Available at: https:// medone.thieme.com/ebooks/1273913?fromSearch=true\#/ ebook_1273913_SL54677488. Accessed March 1, 2020

4 Konar SK, Maiti TK, Bir SC, Kalakoti P, Nanda A, Robert H. Robert H. Pudenz (1911-1998) and ventriculoatrial shunt: historical perspective. World Neurosurg 2015;84(5):1437-1440

5 Pudenz RH. Experimental and clinical observations on the shunting of cerebrospinal fluid into the circulatory system. Clin Neurosurg 1957-1958;5:98-114

6 Pudenz RH, Russell FE, Hurd AH, Shelden CH. Ventriculoauriculostomy; a technique for shunting cerebrospinal fluid into the right auricle; preliminary report. J Neurosurg 1957;14(2):171-179

7 Evangelos D, Dimitrios G, Georgios S, Nikolaos E, Filippos P, Marios T. Percutaneous placement of the peripheral catheter to the subclavian vein for a VA shunt. Pan Afr Med J 2017. Doi: 10.11604/pamj.2017.27.42.11374

8 Sorge O, Vitzthum HE, Schaffranietz L, Günther L, Trantakis C. [A new set for percutaneous implantation of the cardiac catheter in ventriculo-atrial shunt systems. A new technical note]. Zentralbl Neurochir 1994;55(2):125-127

9 Słowiński J, Stomal M, Skaba T, Pieniazek J, Mrówka R. [Percutaneous ventriculoatrial shunt: experience with 179 cases]. Neurol Neurochir Pol. 40(3):198-202.

10 Harrison MJ, Welling BG, DuBois JJ. A new method for inserting the atrial end of a ventriculoatrial shunt. Technical note. J Neurosurg 1996;84(4):705-707 